\title{
CARACTERÍSTICAS AGRONÔMICAS DE GENÓTIPOS DE FEIJOEIRO CULTIVADOS NAS ÉPOCAS DA SECA E DAS ÁGUAS ( ${ }^{1}$ )
}

\author{
ROGÉRIO FARINELLI $\left({ }^{2 *}\right) ;$ LEANDRO BORGES LEMOS $\left({ }^{2,3}\right)$
}

\begin{abstract}
RESUMO
O feijão é um dos alimentos produzidos em maior quantidade em todo o território nacional, sendo intensa a busca por cultivares produtivas e adaptadas ao local de cultivo. Assim, desenvolveu-se um trabalho, em Botucatu (SP), com o objetivo de avaliar as características agronômicas de genótipos de feijoeiro, visando obter informações sobre aqueles com melhor desempenho produtivo. O experimento foi desenvolvido em três safras, correspondendo à época da seca de 2005, das águas de 2005 e da seca de 2006. O delineamento experimental utilizado foi o de blocos casualizados, com 24 tratamentos, representados pelos genótipos de feijoeiro (grupo comercial carioca e preto), com quatro repetições. Em todos os genótipos de feijoeiro o desenvolvimento agronômico foi satisfatório, destacando-se os genótipos Gen 96A28-P7-1-1-1-1, Pérola, OP-S-16, OP-NS-331, Gen 96A28-P4-1-1-1-1 e CNFC 8065 quanto ao número de vagens por planta, à massa de cem grãos, renda e consequentemente maior produtividade de grãos.
\end{abstract}

Palavras-chave: Phaseolus vulgaris, cultivares, componentes da produção e produtividade de grãos.

\section{ABSTRACT \\ AGRONOMIC CHARACTERISTICS IN COMMON BEAN GENOTYPES IN DRY AND SUMMER SEASONS}

The common bean is one of foods produced in bigger amount in all national territory, being intense the search for yield cultivars, adaptability and desirable technological characteristics. The research was carried in Botucatu (SP), with objective of evaluating the behavior of common bean genotypes, how the agronomic aiming at to select those that better yield performance. The experiment was developed in three harvests, having corresponded the dry growing season 2005, summer 2005 and dry 2006. The experimental design used was randomized blocks, with 24 treatments, represented for the common bean genotypes, with four replications. All the common bean genotypes had presented satisfactory agronomic performance, being distinguished the genotypes Gen 96A28-P7-1-1-1-1, Pérola, OP-S-16, OP-NS-331, Gen 96A28-P4-1-1-1-1 e CNFC 8065 how the number of pods for plant, 100 grains mass, rend and yield.

Key words: Phaseolus vulgaris L., cultivars, yielding components, yield.

$\left({ }^{1}\right)$ Recebido para publicação em 28 de janeiro de 2009 e aceito em 20 de agosto de 2009.

$\left({ }^{2}\right)$ Departamento de Produção Vegetal, Faculdade de Ciências Agrárias e Veterinárias, Universidade Estadual Paulista (UNESP), 14884-000 Jaboticabal (SP). E-mail: rfarinelli@fcav.unesp.br (*) Autor correspondente; leandrobl@fcav.unesp.br

$\left({ }^{3}\right)$ Bolsista do CNPq. 
As atividades de pesquisa vêm se tornando competitivas, a fim de promover a geração e divulgação de cultivares com características agronômicas desejáveis, resistência a insetos-praga e doenças, tolerância à seca, elevado potencial produtivo, adaptadas às regiões de cultivo e associado à obtenção de grãos de acordo com a preferência do mercado consumidor (RAMALHO e ABREU, 2006).

A partir da década de 80, passou-se a cultivar o feijoeiro na época de inverno (terceira safra), almejando-se a produtividade em $1500 \mathrm{~kg} \mathrm{ha}^{-1}$, o que exigia mais tecnologia, principalmente do uso de irrigação. Na década de 90, os produtores de feijão, fazendo uso de maiores níveis tecnológicos em todas as safras, buscavam produtividades de 2500 a 3000 $\mathrm{kg} \mathrm{ha}^{-1}$. Foi nesse período que foi lançada a cultivar Pérola, com resistência a algumas doenças foliares, presença de grãos graúdos e altamente produtiva, com potencial de $4000 \mathrm{~kg} \mathrm{ha}^{-1}$ (Үокоунма et al., 2000). Atualmente, já se constata comercialmente, patamares de produtividade entre 3500 a $4000 \mathrm{~kg} \mathrm{ha}^{-1}$ de grãos, e o potencial da cultura ultrapassa estes valores citados (CARBONELl et al., 2003).

Em virtude do ganho de produtividade que a cultura do feijão vem tendo constantemente, muitas pesquisas foram realizadas objetivando avaliar a interação genótipo $\mathrm{x}$ ambiente (CARBONELL et al., 2001 e 2004; Ribeiro et al., 2004) a fim de estabelecer o comportamento da planta diante das diferentes condições ambientais.

Desse modo, Lemos et al. (2004) e RAMOS JUNIOR et al. (2005), avaliando características agronômicas de genótipos de feijão na época das águas, obtiveram em diferentes anos agrícolas, valores de produtividade de 1449 a $3412 \mathrm{~kg} \mathrm{ha}^{-1}$ e 2251 a $3587 \mathrm{~kg} \mathrm{ha}^{-1}$ respectivamente.

O objetivo deste trabalho foi avaliar o desempenho de genótipos de feijoeiro em duas épocas de cultivo (safra da seca e das águas), quanto às características agronômicas, visando obter informações referentes à capacidade produtiva.

O trabalho foi desenvolvido em Botucatu (SP), localizada a $48^{\circ} 26^{\prime}$ de longitude Oeste e $22^{\circ} 51^{\prime}$ de latitude Sul e altitude de $740 \mathrm{~m}$, com o uso de semeadora-adubadora. Foram abertos sulcos distanciados entre si de $0,45 \mathrm{~m}$, realizando-se simultaneamente a aplicação de $350 \mathrm{~kg} \mathrm{ha}^{-1} \mathrm{da}$ fórmula comercial 8-28-16 + 0,5\% Zn. A semeadura foi efetuada de forma manual, utilizando-se 16 sementes por metro de sulco, sendo realizadas em 16 de fevereiro de 2005 (safra da seca 2005), em 6 de setembro de 2005 (safra das águas 2005) e em 15 de fevereiro de 2006 (safra da seca 2006). Quanto ao atendimento das exigências de água pela cultura do feijoeiro, utilizaram-se para todas as safras a irrigação convencional por aspersão, mediante as fases de desenvolvimento de maior necessidade, alternando turnos de rega de 4 a 5 dias, com uma lâmina de água de aproximadamente $25 \mathrm{~mm}$.

A adubação de cobertura foi efetuada quando, em $50 \%$ das plantas, a $3^{\text {a }}$ folha trifoliada já estava desenvolvida, aplicando-se superficialmente em filete contínuo a $10 \mathrm{~cm}$ da linha da cultura e sem incorporação, $70 \mathrm{~kg} \mathrm{ha}^{-1}$ de $\mathrm{N}$ e de $\mathrm{K}_{2} \mathrm{O}$ respectivamente, utilizando o formulado 20-0-20, seguida de irrigação com lâmina de água de $10 \mathrm{~mm}$.

O delineamento experimental adotado nas três safras foi em blocos casualizados, com 24 tratamentos, representados pelos genótipos de feijoeiro e com quatro repetições. Cada parcela experimental consistiu de quatro linhas de $5 \mathrm{~m}$ de comprimento, espaçadas em 0,45 m, em uma área de 9,0 $\mathrm{m}^{2}$. Consideraram-se as duas linhas centrais como área útil, eliminandose $0,50 \mathrm{~m}$ das extremidades de cada linha, totalizando uma área de $3,6 \mathrm{~m}^{2}$.

Antes da colheita, foram avaliados em dez plantas por parcela experimental, os componentes da produção, representados pelo número de vagens por planta, número de grãos por vagem e massa de cem grãos. A renda (\%) foi determinada tomando-se 300 gramas de grãos por parcela experimental, passando por um conjunto de peneiras, oblonga 12, oblonga 11 e fundo, retirando para pesagem os grãos retidos na peneira oblonga 12 para posterior análise da porcentagem de grãos selecionados. A produtividade de grãos foi obtida pelo arranquio manual das plantas, contidas na área útil de cada parcela, e posterior trilha mecânica, padronizando-se o grau de umidade a $13 \%$.

Os resultados foram submetidos à análise de variância individual (Tabela 1), e posterior à análise conjunta (Tabela 2), uma vez que a razão entre o maior e o menor quadrado médio residual não foi superior a sete (BANZATTO e KRONKA, 1995). Sob a presença das interações significativas foram realizados os desdobramentos necessários. As médias foram comparadas pelo teste de agrupamento de SCOTT-KNOTT (1974) para a avaliação dos efeitos dos genótipos e teste de Tukey para as safras (seca de 2005, águas de 2005 e seca de 2006), em nível de $5 \%$ de probabilidade.

Verifica-se nas tabelas 1 e 2 , a precisão experimental do respectivo trabalho, em que os valores dos coeficientes de variação $(\mathrm{CV})$ permaneceram dentro dos limites máximos propostos por OLIVEIRA et al. (2009), em ensaios com a cultura do feijão, que determinaram os valores de $\mathrm{CV}$ aceitáveis em relação às características: vagens por planta $(26,30 \%)$, grãos por vagem $(18,35 \%)$, massa de cem grãos $(11,30 \%)$ e produtividade $(24,86 \%)$. 
Tabela 1. Resumo da análise de variância individual para o número de vagens por planta, número de grãos por vagem, massa de 100 grãos, renda e produtividade dos genótipos de feijoeiro cultivados nas safras da seca 2005, águas 2005 e seca 2006. Botucatu (SP)

\begin{tabular}{|c|c|c|c|c|}
\hline \multirow{2}{*}{ Variáveis } & \multirow{2}{*}{ Parâmetros } & \multicolumn{3}{|c|}{ Safras } \\
\hline & & Seca 2005 & Águas 2005 & Seca 2006 \\
\hline \multirow[t]{3}{*}{ Vagens por planta } & F Genótipos & $3,20 * *$ & $3,74^{* *}$ & $2,40 * *$ \\
\hline & Média & 11,0 & 16,5 & 15,8 \\
\hline & $\mathrm{CV}(\%)$ & 27,4 & 17,7 & 20,4 \\
\hline \multirow[t]{3}{*}{ Grãos por vagem } & F Genótipos & $2,36 * *$ & $1,58^{* *}$ & $2,28^{* *}$ \\
\hline & Média & 4,5 & 5,1 & 4,9 \\
\hline & $\mathrm{CV}(\%)$ & 11,9 & 10,6 & 9,2 \\
\hline \multirow[t]{3}{*}{ Massa de 100 grãos } & F Genótipos & $6,25^{* *}$ & $2,58^{* *}$ & $5,55^{* *}$ \\
\hline & Média & 26,5 & 22,1 & 21,7 \\
\hline & $\mathrm{CV}(\%)$ & 6,9 & 10,6 & 9,4 \\
\hline \multirow[t]{3}{*}{ Renda } & F Genótipos & $4,96^{* *}$ & $10,73^{* *}$ & $10,85^{* *}$ \\
\hline & Média & 73,0 & 68,5 & 75,7 \\
\hline & $\mathrm{CV}(\%)$ & 9,8 & 12,0 & 6,9 \\
\hline \multirow[t]{3}{*}{ Produtividade } & F Genótipos & $2,70 * *$ & $7,40^{* *}$ & $4,28^{* *}$ \\
\hline & Média & 4157 & 4845 & 4564 \\
\hline & $\mathrm{CV}(\%)$ & 9,8 & 8,3 & 9,6 \\
\hline
\end{tabular}

** Significativo a $1 \%$ de probabilidade.

Tabela 2. Resumo da análise de variância conjunta para o número de vagens por planta, número de grãos por vagem, massa de cem grãos, renda e produtividade dos genótipos de feijoeiro cultivados nas safras da seca 2005, águas 2005 e seca 2006. Botucatu (SP)

\begin{tabular}{lccccc}
\hline \multirow{2}{*}{ Causas da Variação } & \multicolumn{4}{c}{ Variáveis } \\
\cline { 2 - 6 } & Vagens por planta & Grãos por vagem & Massa de 100 grãos & Renda & Produtividade \\
\hline F Safras (S) & $90,50^{* *}$ & $31,79^{* *}$ & $151,42^{* *}$ & $22,20^{* *}$ & $62,73^{* *}$ \\
F Genótipos (G) & $3,47^{* *}$ & $4,31^{* *}$ & $10,54^{* *}$ & $19,17^{* *}$ & $9,43^{* *}$ \\
S x G & $2,91^{* *}$ & $0,91^{* *}$ & $1,39^{*}$ & $2,56^{* *}$ & $2,07^{* *}$ \\
Média & 14,4 & 4,8 & 23,5 & 72,3 & 4522 \\
CV $(\%)$ & 21,0 & 10,6 & 8,9 & 10,1 & 9,4 \\
\hline
\end{tabular}

** Significativo a $1 \%$ de probabilidade.

Para o número de vagens por planta, os genótipos LP 98-123, OP-S-16, Gen 96A28-P4-1-1-1-1 e CNFC 8065 alcançaram resultados superiores principalmente para as safras das águas de 2005 e seca de 2006. Ao passo que Gen 96A55-P16-1-1, CNFP 7966 e Gen 96A10 foram os que menos produziram vagens por planta, não tendo sido estabelecidos diferenças significativas entre as safras (Tabela 3).

Os resultados para os dois componentes da produção (número de vagens por planta e grãos por vagem) foram semelhantes ao verificado por LEMOs et al. (2004, 2005) e RAmos Junior et al. (2005).

Em relação à massa de cem grãos e a renda, nota-se que novamente os genótipos OP-S-16, Gen 96A58-P3-4-1-1, Gen 96A28-P4-1-1-1-1 também se destacaram, juntamente com Pérola, OP-NS-331 e Gen 96A28-P7-1-1-1-1. Neste caso, a maior massa unitária de grãos possibilitou maior quantidade de grãos de tamanho superior (Tabelas 3 e 4).

Analisando os componentes da produção, observa-se de maneira geral uma relação existente principalmente para vagens por planta, massa de cem grãos e renda, o que possibilitaram para os genótipos Gen 96A28-P7-1-1-1-1, Pérola, OP-S-16, OP-NS-331, Gen 96A28-P4-1-1-1-1 e CNFC 8065 maiores produtividades de grãos em relação aos demais, com valores de 4230 a $5500 \mathrm{~kg} \mathrm{ha}^{-1}$. Contudo, apenas os genótipos Pérola, OP-S-16 e Gen 96A28-P4-1-1-1-1 obtiveram altas produtividades nas três safras estudadas (Tabela 4 ). 


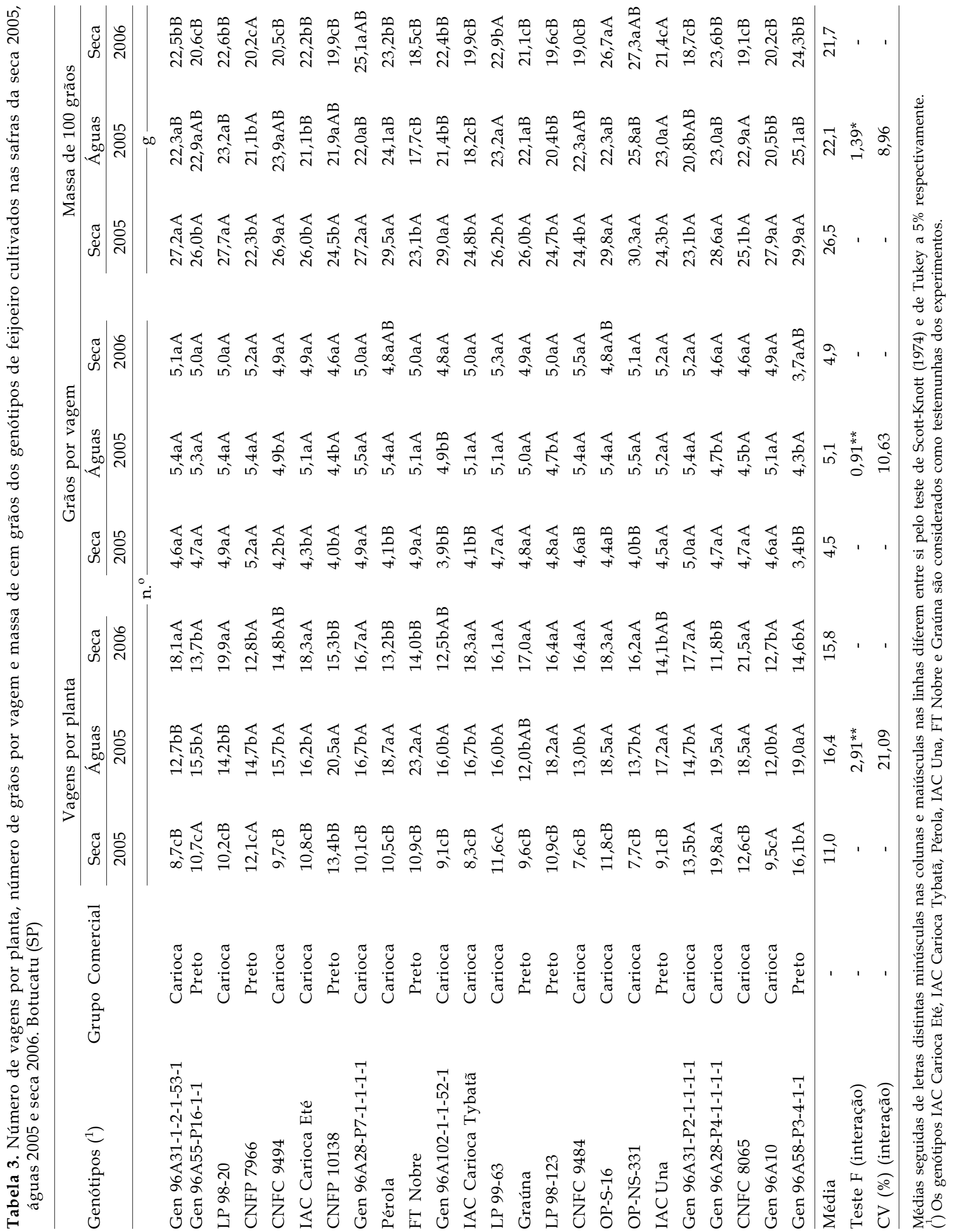




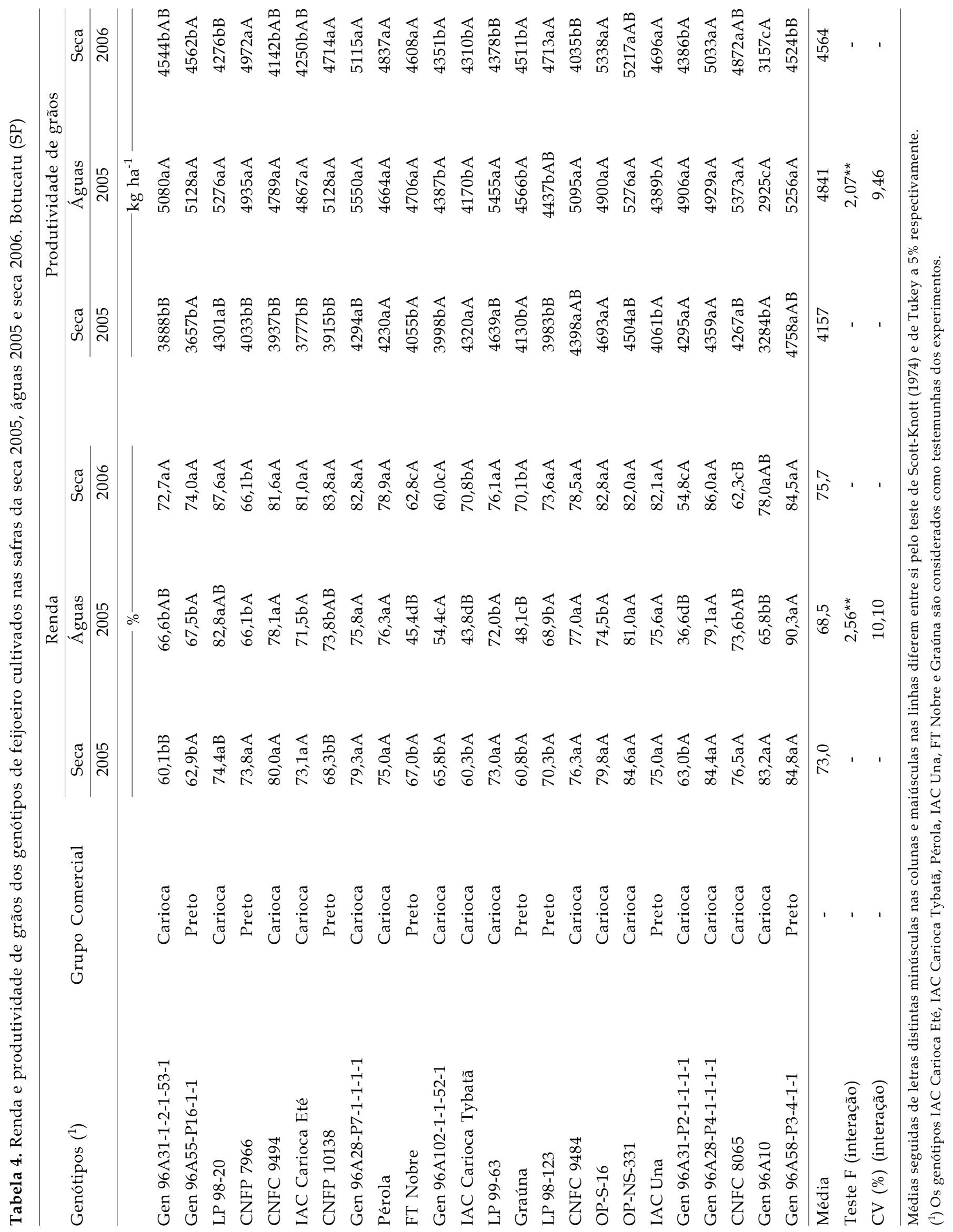


Os resultados de produtividade observados no respectivo trabalho (Tabela 4) demonstraram novamente o potencial produtivo do feijoeiro, sendo superiores aos obtidos na literatura, especificamente para o Estado de São Paulo e de acordo com as épocas estudadas (CARBOnell et al. 2003; Lemos et al. 2004; RAmOS Junior et al. 2005). Além disso, as diferenças para a produtividade de grãos entre os genótipos de feijoeiro, como também para as épocas de semeadura refletem a interação genótipo-ambiente, relatado por CARbONell et al. (2001 e 2004) e Ribeiro et al. (2004).

O fato de tais genótipos de feijoeiro alcançarem maiores produtividades de grãos mediante número de vagens por planta, massa de cem grãos e renda pode ser indicativo do efeito benéfico desses componentes no rendimento final. Estas três características agronômicas tornam-se importantes na seleção de genótipos de feijoeiro mais produtivos, sabendo, é claro, que a variação dos componentes da produção do feijoeiro colabora com a manutenção da estabilidade da produtividade de grãos.

Destacaram-se nas três safras estudadas os genótipos Gen 96A28-P7-1-1-1-1, Pérola, OP-S-16, OP-NS331, Gen 96A28-P4-1-1-1-1 e CNFC 8065 quanto ao número de vagens por planta, à massa de cem grãos, renda e consequentemente maior produtividade de grãos.

\section{REFERÊNCIAS}

BANZATTO, D.A.; KRONKA, S.N. Experimentação Agrícola. 3.ed. Jaboticabal: FUNEP, 1995. 247p.

CARBONELL, S.A.M.; AZEVEDO FILHO, J.A.; DIAS, L.A.S.; GARCIA, A.A.F.; MORAIS, L.K. Common bean and lines interactions with environments. Scientia Agrícola, v.61, p.169177, 2004

CARBONELL, S.A.M.; AZEVEDO FILHO, J.A.; DIAS, L.A.S.; GONÇALVES, C.; ANTONIO, C.B. Adaptabilidade e estabilidade de produção de cultivares e linhagens de feijoeiro no Estado de São Paulo. Bragantia, v.60, p.69-77, 2001.

CARBONELL, S.A.M.; ITO, M.F.; AZEVEDO FILHO, J.A. de; SARTORI, J.A. Cultivares comerciais de feijoeiro para o Estado de São Paulo: Características e melhoramento. In: CASTRO, J.L.; ITO, M.F. (Coord.). Dia de campo de feijão, 19., 2003, Capão Bonito. Campinas: Instituto Agronômico, 2003. p.5-27 (Documentos IAC, 71)

LEMOS, L.B.; OLIVEIRA, R.S.; PALOMINO, E.C.; SILVA, T.R.B. Características agronômicas e tecnológicas de genótipos de feijão do grupo comercial Carioca, Pesquisa Agropecuária Brasileira, v.39, p.319-326, 2004.

OLIVEIRA, R.L.; MUNIZ, J.A.; ANDRADE, M.J.B.; REIS, R.L. Precisão experimental em ensaios com a cultura do feijão. Ciência e Agrotecnologia, v.33, p.113-119, 2009.
RAMALHO, M.A.P.; ABREU, A.F.B. Cultivares. In: VIEIRA, C.; PAULA JUNIOR, T.J.P.; BORÉM, A. (Ed.). Feijão: 2.ed. Viçosa: Universidade Federal de Viçosa, 2006. p.415-436.

RAMOS JUNIOR, E.U.; LEMOS, L.B.; SILVA, T.R.B. Componentes da produção, produtividade de grãos e características tecnológicas de cultivares de feijão. Bragantia, v.64, p.75-82, 2005.

RIBEIRO, N.D.; JOST, E.; POSSEBON, S.B.; CARGNELUTTI FILHO, A. Adaptabilidade e estabilidade de cultivares registradas de feijão em diferentes épocas de semeadura para a depressão central do Rio Grande do Sul. Ciência Rural, v.34, p.1395-1400, 2004.

SCOTT, A.; KNOTT, M. Acluster-analysis method for grouping means in the analysis of variance. Biometrics, v.30, p.507-512, 1974.

YOKOYAMA, L.P.; WETZEL, C.T.; VIEIRA, E.H.N.; PEREIRA, G.V. Sementes de feijão: Produção, uso e comercialização. In: VIEIRA, E.H.N.; RAVA, C.A. (Ed.). Sementes de feijão: produção e tecnologia. Santo Antonio de Goiás: EMBRAPA Arroz e Feijão, 2000. p.249-270. 